\section{E-117 EVALUATION OF PATIENT DEATHS AFTER MECHANICAL THROMBECTOMY - A SINGLE CENTER EXPERIENCE}

${ }^{1} \mathrm{~A}$ Kuhn, ${ }^{1} \mathrm{~V}$ Naragum, ${ }^{1} \mathrm{R}$ Catton, ${ }^{1} \mathrm{~J}$ Singh, ${ }^{1} \mathrm{~F}$ Massari, ${ }^{2} \mathrm{~K}$ de Macedo Rodrigues, ${ }^{1} \mathrm{M}$ Gounis, ${ }^{1} \mathrm{~A}$ Puri*. ${ }^{1}$ Division of Neurointerventional Radiology, Department of Radiology and New England Center for Stroke, University of Massachusetts, Worcester, MA; ${ }^{2}$ Greensboro Radiology, Greensboro, NC

\subsection{6/neurintsurg-2021-SNIS.212}

Purpose To evaluate the cause of patient deaths after mechanical thrombectomy in a large volume, single center academic institution.

Material and Methods Retrospective review of our prospectively maintained Neuro IR database and identification of all patients who underwent mechanical thrombectomy for anterior circulation strokes between January 2019 and November 2020. Patient characteristics, site of occlusion and TICI recanalization status was collected. Patients' cause of death was also recorded.

Results A total of 239 anterior circulation stroke cases were identified between January 2019 and November 2020. Site of occlusion was predominantly located at the middle cerebral artery $(64.5 \%)$ followed by occlusions involving the internal carotid artery (29\%). One patient presented with multiple occlusion. A total of 60 stroke patients died (25.1\%). Of these 60 patients, 31 patients the cause of death was determined to have resulted from the patient's stroke. In the remining 29 patients $(48 \%)$ cause of death was due to respiratory failure, cardiac arrest, sepsis, underlying cancer or multiorgan failure/ shock. The mean age of patients who died from stroke related causes was 79.3 years (range 46 to 98 years). Fourteen patients were female. In the patient group who directly died as a result of their stroke, successful TICI $2 \mathrm{~B}$ or higher recanalization was achieved in 28/31 cases (90.3\%).

Conclusion Approximately 50\% of patients who died after mechanical thrombectomy died due to non-neurological causes.

Disclosures A. Kuhn: None. V. Naragum: None. R. Catton: None. J. Singh: None. F. Massari: None. K. de Macedo Rodrigues: None. M. Gounis: 1; C; National Institutes of Health (NIH), the United States - Israel Binational Science Foundation, Anaconda, ApicBio, Axovant, Cerenovus, Cook Medical, Gentuity, Imperative Care, InNeuroCo, Magneto. 2; C; Cerenovus, Imperative Care, phenox, Medtronic Neurovascular, Route 92 Medical, Stryker Neurovascular. 4; C; Imperative Care, InNeuroCo and Neurogami. A. Puri: 1; C; NIH, Stryker Neurovascular, Medtronic, Cerenovus. 2; C; Microvention, QApel, Perfuze Medical, Arsenal Medical, Merit Medical, Stryker Neurovascular, Medtronic, Cerenovus. 4; C; InNeuroCo Inc, Galaxy therapeutics, Agile Medical, Perfuze medical and NTI.

\section{E-118 MINIMALLY INVASIVE FLUPROSCOPY-GUIDED PERCUTANEOUS BLEOMYCIN SCLEROTHERAPY FOR CRANIOFACIAL VENOLYMPHATIC MALFORMATIONS IN CHILDREN}

${ }^{1} \mathrm{~A}$ Kuhn, ${ }^{1} \mathrm{~A}$ Puri, ${ }^{1} \mathrm{C}$ Zoppo, ${ }^{2} \mathrm{~K}$ de Macedo Rodrigues, ${ }^{1} \mathrm{~F}$ Massari, ${ }^{1} \mathrm{M}$ Gounis, ${ }^{1} \mathrm{~J}$ Singh* ${ }^{1}$ Division of Neurointerventional Radiology, Dept of Radiology, New England Center for Stroke Research, University of Massachusetts, Worcester, MA; ${ }^{2}$ Greensboro Radiology, Greensboro, NC

\subsection{6/neurintsurg-2021-SNIS.213}

Purpose To evaluate the effectiveness and safety of imageguided percutaneous bleomycin sclerotherapy as a minimally invasive treatment approach for craniofacial (veno)lymphatic malformations in children and adolescents.

Material and Methods We retrospectively reviewed our prospectively maintained Neuro IR database between January 2018 and June 2020 and identified all children and adolescents (1 to 19 years) who underwent percutaneous fluoroscopy guided bleomycin sclerotherapy for craniofacial (veno) lymphatic malformations. Patient clinical and imaging follow up data was collected.

Results We identified 4 patients (2 female patients) between 20 months and 12 years old who presented with clinical and radiographic craniofacial (veno)lymphatic malformations. Two lesions were macrocystic, 1 microcystic and 1 mixed. No procedural complications ensued. On first follow up examination 2 patients report obvious decrease in size of the malformation which is confirmed with ultrasound and/or visual inspection. One patient subjectively reported minimal decrease in size with the ultrasound evaluation not showing any change from prior to the procedure. One patient who showed initial decrease in size of the lesion already underwent a second sclerotherapy session and is awaiting his next follow up appointment. The other 2 patients are scheduled to undergo their next sclerotherapy session as well. One patient did not reach the first follow up time point yet.

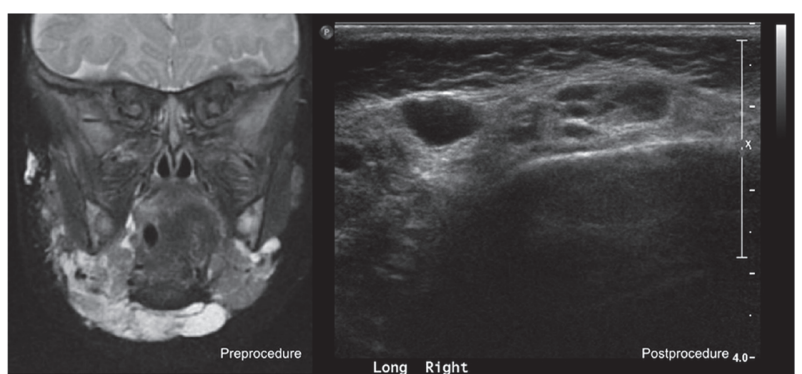

Abstract E-118 Figure 1

\begin{tabular}{|c|c|c|c|c|c|c|c|c|c|}
\hline Patient & Age & Gender & Lesion Location & $\begin{array}{l}\text { Lesion Size } \\
(\mathrm{mm})\end{array}$ & $\begin{array}{l}\text { Lesion } \\
\text { Characteristic }\end{array}$ & $\begin{array}{l}1^{\text {st }} \text { Procedure } \\
\text { Date }\end{array}$ & $\begin{array}{l}\text { Follow up Imaging } \\
\text { Date }\end{array}$ & $\begin{array}{l}\text { Follow up } \\
\text { Results }\end{array}$ & $\begin{array}{l}\text { Retreatment } \\
\text { Date }\end{array}$ \\
\hline 1 & $\begin{array}{l}20 \\
\text { months }\end{array}$ & M & Right parotid, right submandibular and cheek & $40 \times 60 \times 66$ & Mixed & $10 / 31 / 19$ & $7 / 15 / 20$ & Partial cure & $3 / 29 / 21$ \\
\hline 2 & 12 years & $\mathrm{F}$ & $\begin{array}{l}\text { Left posterior Pharynx, left tongue base and } \\
\text { left lower lip }\end{array}$ & $32 \times 10 \times 10$ & Microcystic & $12 / 19 / 19$ & $\begin{array}{l}\text { None, visual } \\
\text { inspection }\end{array}$ & Partial cure & $2 / 8 / 21$ \\
\hline 3 & 3 years & $\mathrm{F}$ & Right mandibular angle & $6 \times 31 \times 32$ & Macrocystic & $11 / 9 / 20$ & $2 / 24 / 21$ & No change & $3 / 29 / 21$ \\
\hline 4 & 11 years & $M$ & Left neck & $46 \times 38 \times 59$ & Macrocystic & $12 / 28 / 20$ & Not yet performed & $\mathrm{n} / \mathrm{a}$ & $\mathrm{n} / \mathrm{a}$ \\
\hline
\end{tabular}

